OPEN ACCESS

Edited by:

Jie Chen,

Chongqing University, China

Reviewed by:

Guimin Zhang,

China University of Mining and

Technology, China

Junbao Wang,

Xi'an University of Architecture and

Technology, China

Jinyang Fan,

Chongqing University, China

*Correspondence:

Lang Liu

csuliulang@163.com

Specialty section:

This article was submitted to

Geohazards and Georisks,

a section of the journal

Frontiers in Earth Science

Received: 27 October 2021

Accepted: 10 January 2022

Published: 14 February 2022

Citation:

Qiu H, Zhang F, Sun W, Liu L, Zhao Y and Huan C (2022) Experimental Study

on Strength and Permeability

Characteristics of Cemented Rock-

Tailings Backfill.

Front. Earth Sci. 10:802818.

doi: 10.3389/feart.2022.802818

\section{Experimental Study on Strength and Permeability Characteristics of Cemented Rock-Tailings Backfill}

\author{
Huafu Qiu ${ }^{1,2}$, Fushun Zhang ${ }^{1,2}$, Weibo Sun ${ }^{1,2}$, Lang Liu ${ }^{1,2 *}$, Yujiao Zhao ${ }^{1,2}$ and Chao Huan ${ }^{1,2}$ \\ ${ }^{1}$ School of Energy Engineering, Xi'an University of Science and Technology, Xi'an, China, ${ }^{2}$ Key Laboratory of Western Mines and \\ Hazards Prevention, Ministry of Education of China, Xi'an, China
}

To study the strength and permeability characteristics of cemented tailings backfill with different cement-sand ratios and different waste rock contents, uniaxial compression strength test and permeability test were carried out respectively. The porosity of cemented tailings backfills after solidification was observed by scanning electron microscope. The effects of cement-sand ratio and waste rock content on the internal porosity and overall permeability of cemented tailings backfill were studied. The test results showed that the cement-sand ratio and waste rock content have certain effects on the strength and permeability of the backfill body. When the cement-sand ratio was fixed, the uniaxial compressive strength and permeability of the backfill body increased first and then decreased with the increase of waste rock content. When the waste rock content was $10 \%$, the uniaxial compressive strength of the backfill body reached the maximum, and when the waste rock content was 30\%, the permeability reached the maximum. Due to the increase of the area of waste rock particles in the cross-section, the area of gas passing rapidly decreased, resulting in the decrease of the permeability growth rate. When the waste stone content was fixed, with the decrease of cement-sand ratio, due to the decrease of cementitious materials, more micro-cracks were produced in the curing process of backfill body, resulting in the decrease of uniaxial compressive strength and the increase of permeability.

Keywords: cemented tailings backfill, waste rock, uniaxial compression strength, permeability, scanning electron microscope

\section{INTRODUCTION}

Backfill mining is an important development direction for safe and green mining in China. The use of solid waste generated in the mining process to fill the goaf can effectively control the deformation and damage of the surrounding rock in the goaf, and prevent the surface subsidence, which can not only ensure the safety of stope but also make full use of the solid waste of mines. It has significant advantages in safe mining, solid waste treatment, environmental protection, and so on (Zhang et al., 2018; Qi and Fourie, 2019; Qi, 2020; Yin et al., 2019; Dong et al., 2019; Liu JG et al., 2020). As the main unit of backfill mining, cement tailings backfill took the solid waste generated in the process of mining as aggregate and cement as cementing material. According to a certain ratio, water was added to fully mix into an appropriate concentration of paste, which was sent into the mine through the pipeline. After solidification, it can be used as an artificial pillar to bear the ground stress in the stope; therefore, its mechanical stability was crucial to the safety of the stope (Zhang et al., 2011a; Zhang 
et al., 2011b; Lin et al., 2013; Hong et al., 2021; Li et al., 2021b; Li et al., 2021c). In addition, the backfill is a porous medium, and the permeation characteristic is also an important quality index of the backfill (Wang et al., 2009). Permeability refers to the degree of difficulty of gas, liquid, or ion permeating, diffusing, or migrating into the specimen under the action of gradient such as pressure concentration. The pores in the backfill are the main path of the permeable medium, the transmission speed of harmful substances in the backfill is directly determined by the permeability, and this kind of permeable medium will have a certain influence on the performance of backfill body. Therefore, permeability is a key judgment index of the durability of the backfill (Yang and Zhu, 2003; Liu et al., 2005; Deng et al., 2006; Shi et al., 2021). The material of the backfill is mostly mine solid waste, and the tailings from the concentrator are mainly used as the aggregate. In the process of mineral processing, agents are usually added, so there will be excessive pollution substances in the tailings. Tailings particles produced by metal mines may contain radioactive components and heavy metal ions such as lead, copper, and zinc ions (Yuan and Xu, 2004; Xu et al., 2008; Zhong et al., 2020; Yao et al., 2021). Therefore, the permeability characteristics of the backfill will be related to whether these harmful substances will flow out with the water seepage of the backfill, resulting in the pollution of the underground environment and even underground water. The permeation characteristics of the backfill are studied to understand its change rule, to better design and prepare the environmentfriendly and high-durability underground backfill artificial pillar.

Chen et al. (2019) conducted experiments on the permeability characteristics of coal rocks filled with pulverized coal with different air pressures and different crack widths, and studied the variation law of the permeability of coal rocks filled with pulverized coal with different particle sizes under the influence of pressure and crack widths. Wang et al. (2010) combined electron microscope photos of artificial sediment filling pores of the rock fracture and rock seepage experiments, and discussed the sediment particles' influence law of fractured rock permeability characteristics; they concluded that rock permeability under the effect of sediment particles significantly decreased, and when sediment particles migrated into the fracture after balance, rock permeability increased gradually and tends to be stable. Qiu et al. (2020) and Qiu et al. (2021) studied the microstructure characteristics of the cemented rock-tailings backfill and its influence on the strength. Wu et al. (2015) studied the influence of different initial temperatures of backfill, cement-sand mass ratio, and curing temperature on the seepage characteristics of backfill through numerical simulation, and concluded that the permeability of backfill decreases with the increase of curing temperature and cement-sand mass ratio. Wang and Xu (2018) carried out constant head permeability test and variable head permeability test for filling materials with different cement-sand ratios and different cement-cement agents. They studied cement-sand ratio, cement-cement composition, and permeability variation characteristics of filling slurry after gradually solidifying, and discussed the influence relationship between the permeability of backfill and the content of cementing material. Scholars have studied the strength characteristics of rock materials and reported relevant results (Fan et al., 2019; Zhu et al., 2019; Fan et al., 2020; Li et al., 2021a). Scholars have studied the permeability characteristics of rock materials and reported the experimental results of influencing factors (Chao et al., 2017; Zhang et al., 2020; Liu et al., 2020a; Liu et al., 2020b). But so far, there are few research reports on the permeability characteristics of cemented tailings backfill. Permeability characteristics of the backfill are aggregate composition, cement-sand ratio, and other factors; considering the impact of filling strength on the stability of feature, waste rock added to the aggregate particles can effectively improve the strength of backfill and better meet the needs of the filling ( $\mathrm{Fu}$ et al., 2014; Ge et al., 2014; Lu et al., 2017), and the addition of waste rock particles has a certain influence on the infiltration characteristics of backfill. Therefore, this article conducted gas permeability tests on cemented tailings backfill with different cement-sand ratios and different waste rock contents, and analyzed the influence of cement-sand ratios and waste rock contents on the permeability characteristics of backfill.

\section{EXPERIMENTAL PROGRAMS AND METHODS}

All tests mainly included backfill specimen preparation, UCS test, permeability test, and SEM test. The overall process of the test is shown in Figure 1.

\subsection{Specimen Preparation}

Tailings from a mine in Shaanxi Province and waste rock particles with a particle size of $3-5 \mathrm{~mm}$ were selected as aggregate, and ordinary Portland cement was used as cementing material. Cemented tailings backfill with different proportions were prepared according to a certain proportion. The cement-sand ratios are 1:4, 1:6, and 1:8; the waste rock contents are $0 \%, 10 \%$, $20 \%, 30 \%$, and $40 \%$; and the material concentration is $76 \%$. According to the designed material ratio, quantitative tailing, waste rock, and cement were weighed and mixed fully, and water was added quantitatively to mix them evenly. The samples were loaded into the cylindrical cast-iron test mold three times. After standing for $48 \mathrm{~h}$, the surface of the specimen was scraped flat and demolded.

According to the requirements of two test systems for specimen size, 15 cylindrical specimens with a diameter of $50 \mathrm{~mm}$ and a height of $100 \mathrm{~mm}$ were prepared for the uniaxial compressive strength test, and 15 cylindrical specimens with a diameter of $25 \mathrm{~mm}$ and a height of $50 \mathrm{~mm}$ were prepared for the permeability test. The specimens were marked and placed into the curing box with constant temperature and humidity for curing (temperature of the curing box was $20 \pm 1^{\circ} \mathrm{C}$, the humidity was $95 \pm 1 \%$ ). When the curing period reached 28 days, the waste rock cemented tailings backfill specimen was taken out.

\subsection{Uniaxial Compression Strength Test}

A standard specimen $(\varnothing 50 \mathrm{~mm} \times 100 \mathrm{~mm})$ with a curing period of 28 days was taken out, and both ends of the specimen were polished to ensure that the two ends of the specimen were smooth 

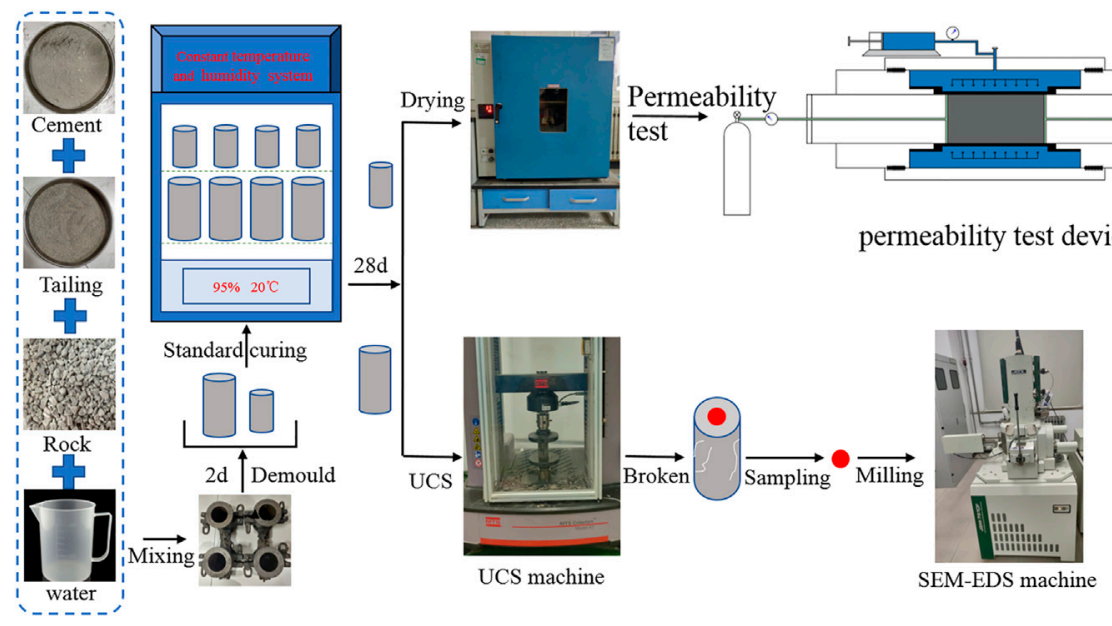

FIGURE 1 | Experimental flow chart.

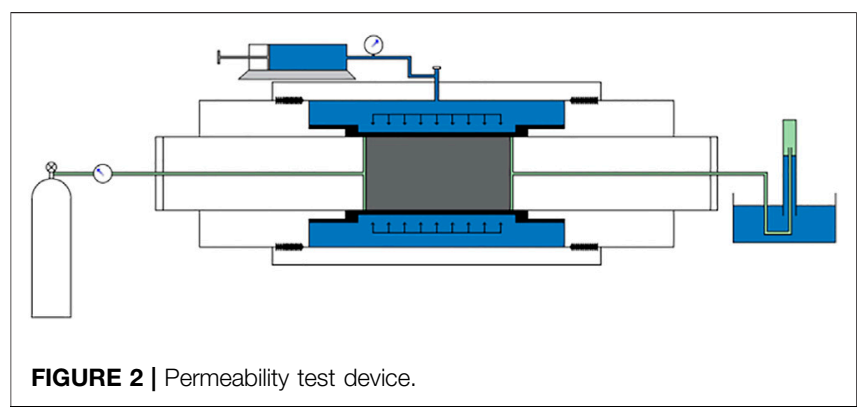

and flat. After treatment, the specimens were subjected to the uniaxial compression strength test. The uniaxial press was used as MTS rock mechanical loading system in the test, and the constant displacement loading mode with a loading rate of $1 \mathrm{~mm} / \mathrm{min}$ was used to load the specimens until they were destroyed.

\subsection{Permeability Test}

\subsubsection{Permeability Test Device}

This experiment using the gas penetration testing device is shown in Figure 2. The whole device was composed of three parts: the left side inlet section; a black rubber middle holster package part for hydraulic confining pressure region into the specimen by its surrounding space with water, fully squeezing the rubber holster package backfill specimen and providing the confining pressure; and the right end tank that adopts the inverted cylinder method for gas collection and recording. The permeation medium selected in this experiment was nitrogen.

\subsubsection{Air Tightness Inspection}

Before the test, the prepared test piece was put in to check the whole device, first turning the confining pressure push water knob for pressurization, observing whether the confining pressure gauge is stable, checking whether there is water leakage at both ends, and determining whether there is rupture damage inside the device's black rubber leather. Then the nitrogen cylinder knob was opened to check the unblocked test pipeline and airtightness. It is important to ensure that the black rubber plant holster is not ruptured, and the pipe flow is steady and airtight according to the strength of the specimens; to set the test gas inlet pressure in the process of choosing the appropriate confining pressure, the confining pressure should be greater than the test air inlet pressure to ensure that there will be no damage to the specimen during the test and that there is enough tightness.

\subsubsection{Specimen Preparation}

The small specimens $(\varnothing 25 \mathrm{~mm} \times 50 \mathrm{~mm})$ were taken out from the curing box for grinding to ensure the flatness of both ends of the specimen and the smoothness of the cylinder to avoid gas passing through the specimen and affecting the accuracy of permeability due to the uneven contact surface or the loose wrapping of the black rubber sleeve around the specimen in the test process. The polished specimens were placed in a drying oven for drying for $24 \mathrm{~h}$ to ensure that all specimens were fully dried.

\subsubsection{Test Steps}

According to the uniaxial compression strength test, the minimum uniaxial compressive strength of the backfill specimen was $0.684 \mathrm{MPa}$. To ensure that the specimen in the test process will not be destroyed and affect the test results, the confining pressure was set to $0.8 \mathrm{MPa}$ and the air inlet pressure was set to $0.1 \mathrm{MPa}$. Before the test, the diameter and length of the dried specimen were measured and recorded with Vernier calipers. After the measurement, the specimen was put into the device for permeability test in accordance with the marked order. After placing the specimen in the center of the device, the water injection knob was slowly rotated to adjust the confining pressure to $0.8 \mathrm{MPa}$. After the confining pressure was stabilized, the cylinder was opened to adjust the inlet pressure and slowly adjust the inlet pressure to $0.1 \mathrm{MPa}$. After the pressure gauge was stable, the outlet pipe was inserted into the measuring cylinder in the water tank for gas collection, and timing was started. Then $10 \mathrm{ml}$ of gas was collected through the measuring cylinder, the time consumed was 
TABLE 1 | Permeability test data of samples with different waste rock contents with cement-sand ratio of 1:4.

\begin{tabular}{|c|c|c|c|c|c|c|}
\hline No & $\begin{array}{c}\text { Backfill length } \\
(\mathrm{mm})\end{array}$ & $\begin{array}{l}\text { Backfill diameter } \\
\text { (mm) }\end{array}$ & Time (s) & $\begin{array}{l}\text { Flow rate } \\
\left(\mathrm{mm}^{3} / \mathrm{s}\right)\end{array}$ & Permeability (md) & Average value \\
\hline \multirow[t]{5}{*}{ Q1 } & 4.983 & 2.504 & 27.37 & 0.490918017 & 4.32242503 & 4.310190499 \\
\hline & 4.983 & 2.504 & 27.46 & 0.48972415 & 4.308258306 & \\
\hline & 4.983 & 2.504 & 27.37 & 0.491877309 & 4.32242503 & \\
\hline & 4.983 & 2.504 & 27.62 & 0.490439772 & 4.28330098 & \\
\hline & 4.983 & 2.504 & 27.42 & 0.492599243 & 4.314543147 & \\
\hline \multirow[t]{5}{*}{ Q2 } & 5.006 & 2.498 & 15.70 & 0.641320288 & 7.606525991 & 7.554918172 \\
\hline & 5.006 & 2.498 & 15.74 & 0.639690503 & 7.587195556 & \\
\hline & 5.006 & 2.498 & 15.72 & 0.640504359 & 7.596848477 & \\
\hline & 5.006 & 2.498 & 15.96 & 0.630872714 & 7.482610154 & \\
\hline & 5.006 & 2.498 & 15.92 & 0.632457822 & 7.501410682 & \\
\hline \multirow[t]{5}{*}{ Q3 } & 4.958 & 2.459 & 13.82 & 0.728562122 & 8.83204861 & 8.844898813 \\
\hline & 4.958 & 2.459 & 13.76 & 0.731738991 & 8.87056045 & \\
\hline & 4.958 & 2.459 & 13.85 & 0.726984009 & 8.812917819 & \\
\hline & 4.958 & 2.459 & 13.77 & 0.731207591 & 8.864118503 & \\
\hline & 4.958 & 2.459 & 13.80 & 0.729618009 & 8.844848681 & \\
\hline \multirow[t]{5}{*}{ Q4 } & 4.952 & 2.47 & 11.78 & 0.854730774 & 10.25702627 & 10.23981506 \\
\hline & 4.952 & 2.47 & 11.73 & 0.858374128 & 10.30074761 & \\
\hline & 4.952 & 2.47 & 11.86 & 0.848965305 & 10.18783891 & \\
\hline & 4.952 & 2.47 & 11.78 & 0.854730774 & 10.25702627 & \\
\hline & 4.952 & 2.47 & 11.85 & 0.849681732 & 10.19643624 & \\
\hline \multirow[t]{5}{*}{ Q5 } & 4.988 & 2.849 & 16.64 & 0.605091858 & 7.202833212 & 7.11643458 \\
\hline & 4.988 & 2.849 & 17.19 & 0.585731735 & 6.97237607 & \\
\hline & 4.988 & 2.849 & 16.80 & 0.599329079 & 7.1342348 & \\
\hline & 4.988 & 2.849 & 16.78 & 0.600043416 & 7.14273806 & \\
\hline & 4.988 & 2.849 & 16.81 & 0.598972547 & 7.129990758 & \\
\hline
\end{tabular}

recorded, and the permeability of the backfill specimen was calculated with the following calculation formula:

$$
K=\frac{Q \times L \times \mu}{\Delta P \times A}
$$

where $Q-$ the flow rate of permeable medium through specimen per unit time $\left(\mathrm{cm}^{3} / \mathrm{s}\right), \mu$-the viscosity of the permeable medium (Pa.s), L-length of specimen $(\mathrm{cm}), \Delta P$-the pressure difference of the permeable medium before and after passing the specimen $(\mathrm{MPa})$, and $\mathrm{A}$-the cross-sectional area through which the permeable medium passes $\left(\mathrm{cm}^{2}\right)$.

\subsubsection{Data Results}

Due to the length of the article, Table 1 shows the data of permeability test for waste rock content with a cement-sand ratio of 1:4. As can be seen from the table, the lowest permeability of the sample with a 1:4 cement-sand ratio of whole tailings was $4.31 \mathrm{md}$. With the increase of waste rock content, the permeability of the sample gradually increased. When the waste rock content reached $30 \%$, the permeability was $10.24 \mathrm{md}$, which was the highest value. When waste rock particles were added to $40 \%$, it was found that the permeability decreased at this time.

\section{RESULTS AND DISCUSSION}

\subsection{Uniaxial Compression Strength Characteristics}

The histogram of uniaxial compressive strength of backfill was drawn, as shown in Figure 3. It can be seen from the figure that,

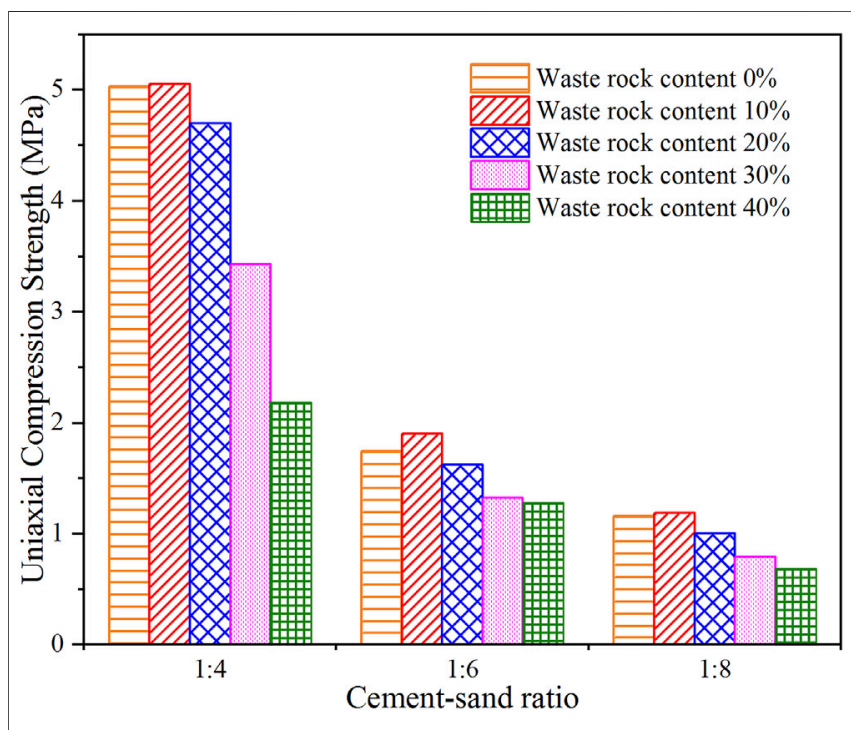

FIGURE 3 | Histogram of uniaxial compressive strength.

with the increase of waste rock content, the uniaxial compressive strength of the three cement-sand ratios of backfill body increased first and then decreased. Among the five waste rock content ratios designed, the strength of backfill body reached the highest when the waste rock content reached $10 \%$. With the decreased of cement-sand ratio, the strength of the backfill decreased gradually.

When the cement-sand ratio was constant, adding a small amount of waste stone particles with large particle size can reduce 

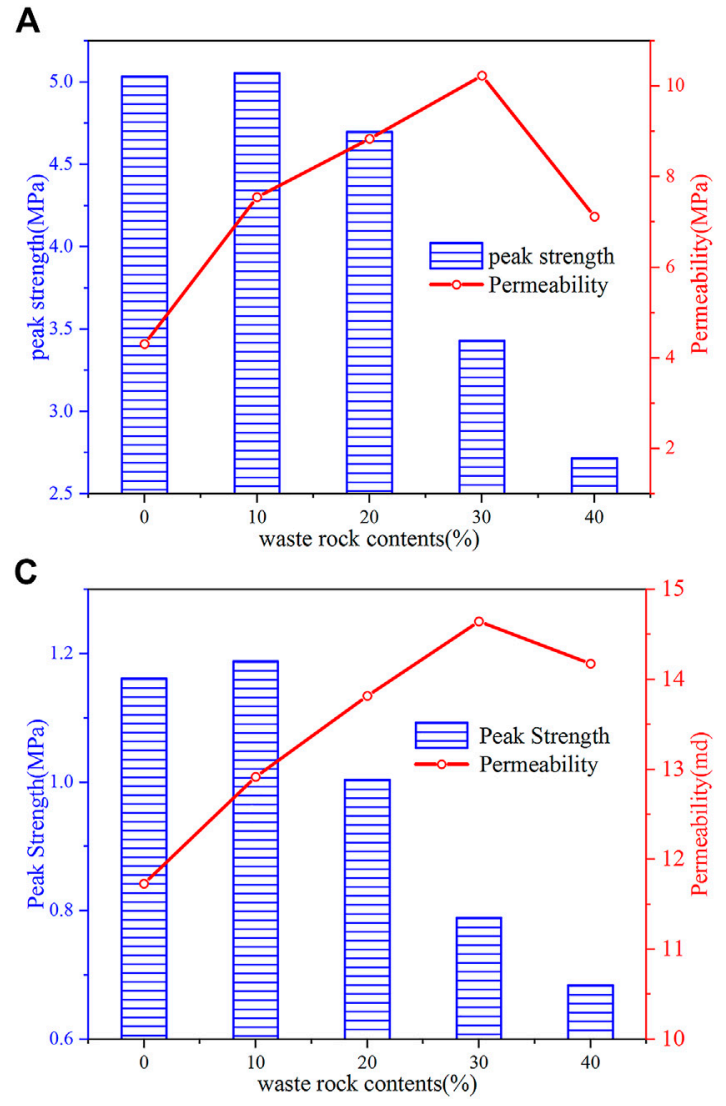

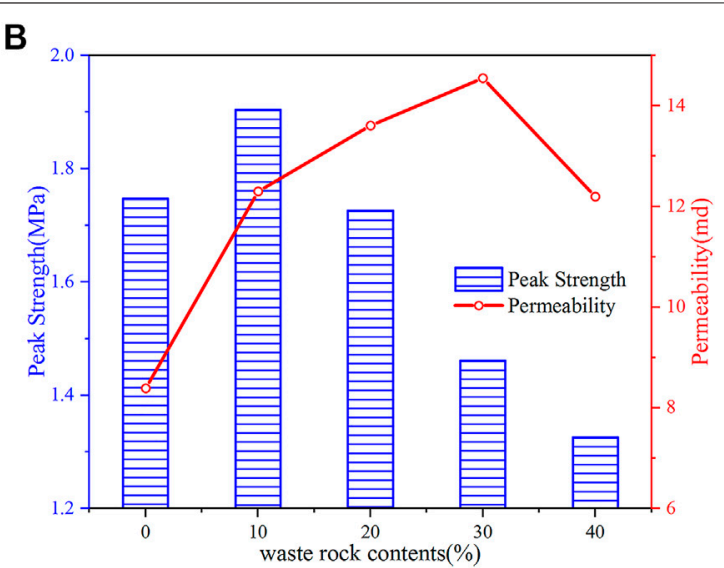

D

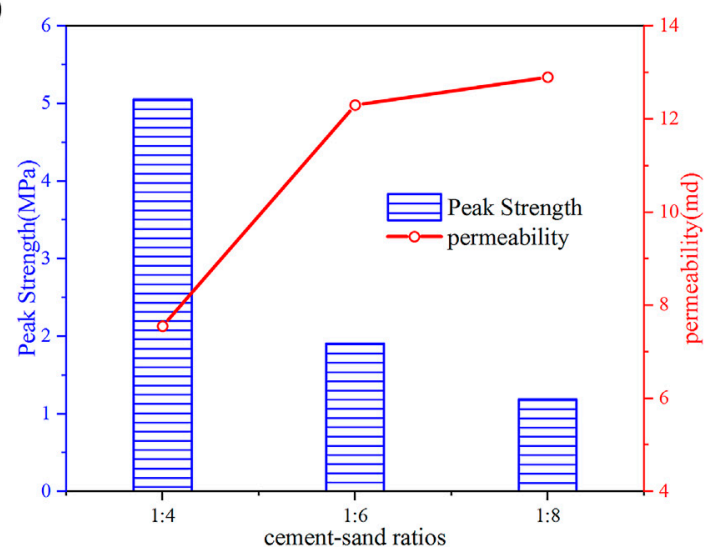

FIGURE 4 | Strength histogram and permeability curve: (A) cement-sand ratio 1:4; (B) cement-sand ratio 1:6; (C) cement-sand ratio 1:8; (D) waste rock content $10 \%$

the specific surface area of aggregate. In contrast, the content of cementitious materials per unit area increased, and the gelation effect was improved. Moreover, the waste rock particles fully wrapped by cement can prevent the propagation and coalescence of cracks in the specimen under uniaxial compression, effectively inhibiting the growth of cracks in the backfill body during uniaxial compression, thereby improving its uniaxial compressive strength.

The waste rock particles continue to increase due to the increase of large particle aggregates; cement cannot fully cover all waste stone particles because after solidification, there were more primary pores, thus forming a low strength area. In the process of uniaxial compression strength test, the region was more prone to cracks, and more likely to expand, resulting in the decrease of uniaxial compressive strength of the backfill body.

When the waste stone content of the backfill body was constant, the uniaxial compressive strength and stability of the backfill body decreased significantly with the continuous decrease of the cement-sand ratio. The smaller the cement-sand ratio, the more direct is the decrease of the cement content in the slurry. The gelling effect of the backfill body in the curing process was decreased, and the uniaxial compressive strength decreased after curing.

\subsection{Permeability Characteristics \\ 3.2.1 Influence of Waste Rock Content on Permeability Characteristics}

The uniaxial compressive strength and permeability of backfill with different waste rock contents and cement-sand ratios were drawn, as shown in Figure 4. According to Figure 4, the permeability variation curve of backfill body was analyzed by referring to the uniaxial compressive strength histogram. When the cement-sand ratio of the backfill body was fixed, the permeability of the three cement-sand ratios of backfill body changed in a similar trend with the increase of waste rock content, which all increased first and then decreased with the increase of waste rock content in the specimen.

The surface of the dirt particles was smoother and the waste rock particle size was larger when adding a certain amount of waste rock filling pulp after particles, filling materials in the process of solidification, and backfilling particles with waste rock particles formed between contact cementation or pore type cementation; backfilling of cementation effect between the particle and dirt particles was reduced, and the specimen within the pore content increased. In the permeability test, these pores greatly shorten the permeability path of the permeable gas in the backfill body, resulting in the improvement of the gas 

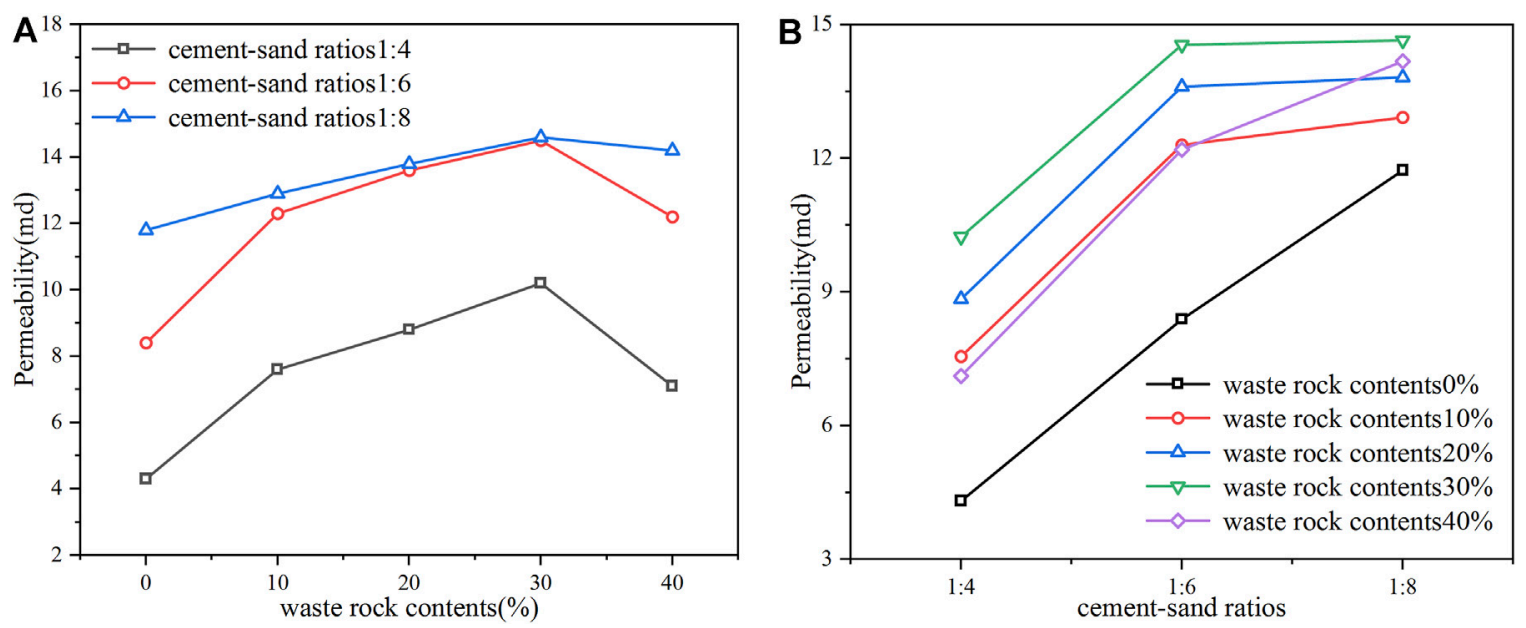

FIGURE 5 | Permeability fluctuation curve: (A) different waste rock contents; (B) different cement-sand ratios.

permeability of the whole specimen. As the waste rock content continues to increase, the tailings particles and cementing materials between waste rock particles become less and less, and the pores formed between waste rock particles became more and more, and the permeability of backfill body became more and more.

When the waste rock content was too much, the waste rock particles occupy a large area in the cross-section of the backfill body, and the cross-sectional area of the cemented tailings for rapid passage of gas decreases. Moreover, the permeability of waste rock particles was far less than that of whole tailings cemented backfill, and there were more waste rock particles that need to be permeated by gas per unit area, leading to a decrease in the permeability of the backfill body. However, waste rock particles lead to a large increase in primary pores inside the backfill body, so the permeability was still higher than that of whole tailings.

\subsubsection{Influence of the Change of the Material Ratio on Permeability Characteristics}

Dot-line diagrams with different waste rock contents and different lime-sand permeabilities were drawn, as shown in Figure 5. It can be seen from Figure 5A that the permeability growth rate of the backfill body decreased with the increase of the waste rock content.

This was due to the increase of waste rock particles in the backfill body, resulting in more primary pores that formed during the solidification process, which promotes the increase of the permeability of the backfill body. However, as waste rock particles increase, the area occupied by waste rock particles in the crosssection increases, and the cross-sectional area of the tailings cemented part through which gas can pass quickly decreases, which had a certain inhibitory effect on the increase in permeability. Under the combined effect of the two, the growth rate of the permeability of the backfill body showed a downward trend.
Observing Figure 5B, it can be found that when the content of waste rock was the same, with the decrease of cement-sand ratio, the increase rate of permeability of backfill body decreases. After adding waste rock particles, when the cement-sand ratio decreased from 1:6 to $1: 8$, the permeability change rate of the specimen decreased obviously.

With the decrease of cement-sand ratio, the cement content in the backfill body decreased directly. The decrease of cement content made it insufficient to completely encapsulate the granular aggregate, and the cementing effect decreases, resulting in more primary pores in the curing process. In the case of whole tailings, the permeability of backfill body was directly affected by cement content. After the waste rock particles were added, the content of primary pores was greater. However, due to the waste rock particles occupying a certain cross-sectional area in the backfill body, the area available for rapid passage of gas in the cross-sectional area was reduced, so it had a certain inhibitory effect on gas permeability. Under the dual effect of the increased of primary pores and waste rock particles, the increase rate of permeability of the backfill body decreased.

\section{SCANNING ELECTRON MICROSCOPY ANALYSIS}

The schematic diagram of the internal pores and cracks of the cemented rock-tailings backfill with different cement-sand ratios was drawn, as shown in Figure 6. When the cement-sand ratio was $1: 4$, the cement content in the backfill body was sufficient, and the larger waste rock particles can be fully wrapped. Only a few small pores were generated during the curing process; with the decrease of cement-sand ratio, the cement content in the backfill body was less and less, the wrapping effect on the larger waste rock particles was gradually weakened, and it was easy to form larger pores or even micro-cracks during the curing process. The pores and micro-cracks in the backfill body greatly shorten 


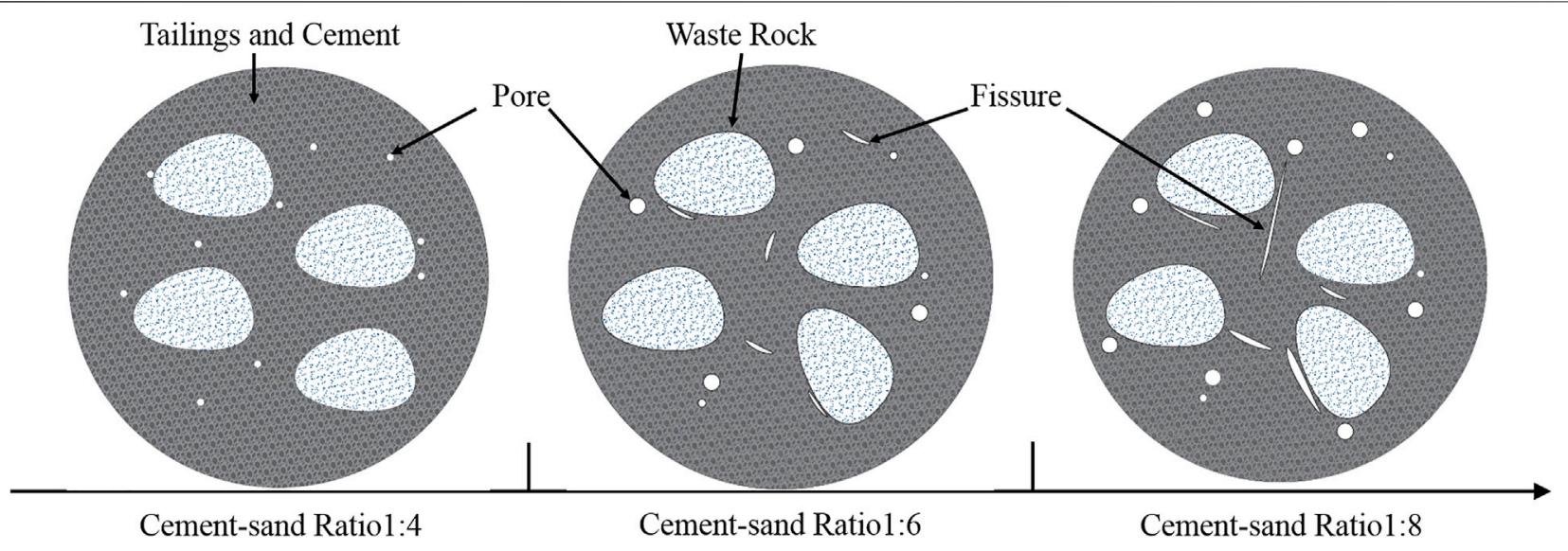

FIGURE 6 | Internal pore diagram of cemented rock-tailings backfill.

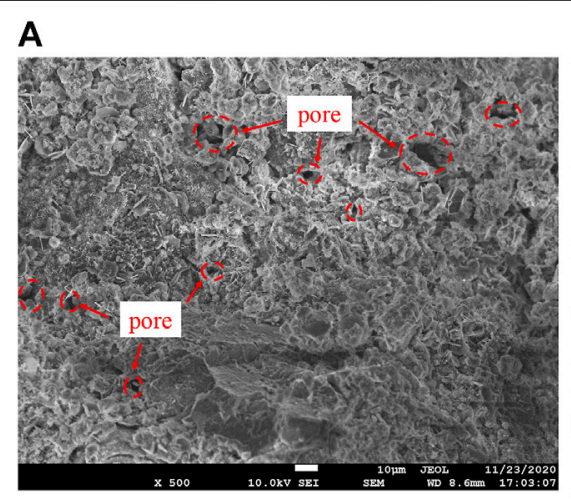

\section{B}

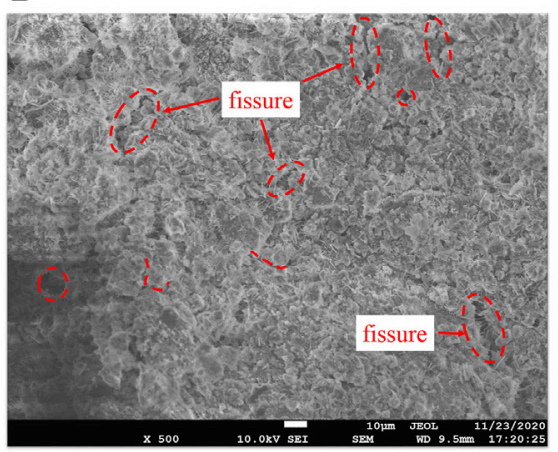

C

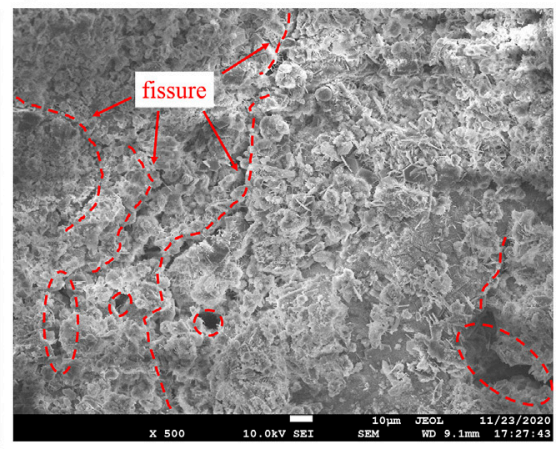

FIGURE 7 | (A) Cement-sand ratio 1:4; (B) cement-sand ratio 1:6; (C) cement-sand ratio 1:8.

the gas penetration path, which was the main influencing factor of its permeability change. To explore the changes of pore structure in the backfill body of this test, the microstructure was observed by scanning electron microscopy.

The backfill body specimens with different cement-sand ratios of $10 \%$ waste rock content were placed in alcohol solution to inhibit hydration. A small sample was cut from the core and scanned by scanning electron microscope. The pore condition was observed at $\times 500$ magnification when taking images. The existence of pores in the specimen was observed by photographs as shown in Figure 7.

It can be seen from Figure 7 $\mathbf{A}$ that when the cement-sand ratio was 1:4, the pore diameter and the number of solidified backfill bodies were small, and there were only individual larger pores; when the cement content was reduced to $1: 6$, it can be seen from Figure 7B that there were not only larger diameter pore structures in the backfill body but also individual banded cracks; when the cement content was further reduced to 1:8, it can be seen from Figure 7C that the internal pore structure of the backfill body was greater, and the diameter was larger. There were long strip cracks, and some cracks were even connected.
When the cement-sand ratio was 1:4, the cement content in the filling material was greater, which can fully cover the aggregate particles, and the overall cementing effect was better in the curing process, so the internal pores were fewer, and the permeability of the backfill body was also low.

When the cement-sand ratio was 1:6, due to the decrease of the cement content of the cementitious material, it was not enough to fully encapsulate the tailings particles, and the overall cementing effect decreases. Contact cementation begins to form between particles, and cracks begin to appear in the curing process. The formation of pore structure and micro-cracks in the backfill body greatly improved the permeability of the specimen.

When the cement-sand ratio was $1: 8$, the further reduction of the cementitious material makes the granular tailings of the backfill body unable to be wrapped by the cementitious material in the curing process. During the curing process, the contact cementation or pore cementation was formed between the aggregate particles, and the aggregate particles cannot be closely connected, resulting in the further increase of the original pores and micro-cracks in the curing process of the backfill body. These cracks greatly shorten the gas permeability path inside the filling material, and the gas permeability of the backfill body was improved. 


\section{CONCLUSION}

In this paper, backfill samples with different lime-sand ratios and waste stone contents were designed and obtained. The strength and permeability characteristics of the backfill were studied by uniaxial compression and gas permeability tests. The microstructure was observed and analyzed by SEM test, and the formation of pores in the backfill was observed to explain its permeability characteristics. Based on the results and discussion, the following conclusions were summarized.

1) When the cement-sand ratio was constant, the uniaxial compressive strength of backfill increased first and then decreased with the increase of waste rock content. Adding an appropriate amount of waste rock particles reduced the specific surface area of solid materials in the backfill body, increased the cement content per unit area, and improved the strength of the backfill body. When the amount of waste rock was too large, the cementation between waste rock particles was weakened and the strength was decreased.

2) When the waste rock content was constant, the uniaxial compressive strength of backfill body increased with the increase of cement-sand ratio. The larger the cement-sand ratio was, the higher the cement content in the backfill was, and the aggregate particles can be fully coated, the cementation effect was good, and the uniaxial compressive strength was greater.

3) When the cement-sand ratio was constant, with the increase of waste rock content, more micro-cracks were formed in the solidification process of backfill, which greatly shorten the permeability path of permeable medium in backfill, and the permeability increased gradually. With the increase of waste rock content in backfill, the number of waste rock particles per unit cross-sectional area increased, which inhibited gas permeability, so the permeability begins to decrease.

\section{REFERENCES}

Chao, Z. M., Wang, H. L., Xu, W. Y., Yang, L. L., and Zhao, K. (2017). Variation of Permeability and Porosity of Sandstones with Different Degrees of Saturation under Stresses. Chin. J. Rock Mech. Eng. 36 (003), 665-680. doi:10.13722/j.cnki. jrme.2016.0063

Chen, J. G., Zheng, Z. S., and Zhang, L. (2019). Seepage Characteristics of Fractures in Coal Rock Filled with Pulverized Coal under Confining Pressure. Saf. Coal Mines 50 (12), 14-17. doi:10.13347/j.cnki.mkaq.2019.12.004

Deng, D. Q., Yao, Z. L., and Yang, Y. Y. (2006). Study on Permeability of HighDensity Slurry Material of Cement-Tailing Backfill. Nonferrous Met. 058 (002), 87-90. doi:10.3969/j.issn.2095-1744.2006.02.023

Dong, L., Tong, X., Li, X., Zhou, J., Wang, S., and Liu, B. (2019). Some Developments and New Insights of Environmental Problems and Deep Mining Strategy for Cleaner Production in Mines. J. Clean. Prod. 210, 1562-1578. doi:10.1016/j.jclepro.2018.10.291

Fan, J., Jiang, D., Liu, W., Wu, F., Chen, J., and Daemen, J. (2019). Discontinuous Fatigue of Salt Rock with Low-Stress Intervals. Int. J. Rock Mech. Mining Sci. 115 (3), 77-86. doi:10.1016/j.ijrmms.2019.01.013

Fan, J., Liu, W., Jiang, D., Chen, J., Tiedeu, W. N., and Daemen, J. J. K. (2020). Time Interval Effect in Triaxial Discontinuous Cyclic Compression Tests and Simulations for the Residual Stress in Rock Salt. Rock Mech. Rock Eng. 53, 4061-4076. doi:10.1007/s00603-020-02150-y
4) The increase of waste rock particles will reduce the growth rate of permeability. The increase of waste rock content led to the increase of primary porosity, which led to the increase of permeability. When the waste rock content was too large, the area of waste rock on the cross-section increased, and the area of gas fast passage decreased, which inhibited the increase of permeability.

5) The primary porosity in the backfill body was the main influencing factor of its permeability. Through SEM test, due to the decrease of cement-sand ratio, the cementation effect of backfill decreased, the content of primary pores increased, and the permeability increased.

\section{DATA AVAILABILITY STATEMENT}

The raw data supporting the conclusion of this article will be made available by the authors, without undue reservation.

\section{AUTHOR CONTRIBUTIONS}

HQ: methodology, conceptualization, supervision, writing-original draft. FZ: methodology, writing-review and editing, data curation. WS: validation, resources. LL: investigation, formal analysis. YZ: validation, formal analysis. $\mathrm{CH}$ : review and editing.

\section{FUNDING}

This work was supported and financed by the Natural Science Fund (Nos. 51904225, 52074212, 52004207, 52104148), the Natural Science Foundation of Shaanxi Province (No. 2020JQ748), and Scientific Research Project of Youth Innovation Team Construction of Shaanxi Provincial Department of Education (No. 21JP077), all of which are greatly appreciated.

Fu, J. X., Du, C. F., and Song, W. D. (2014). Strength Sensitivity and Failure Mechanism of Full Tailings Cemented Backfills. J. Univ. Sci. Techn. Beijing 36 (9), 1149-1157. doi:10.13374/j.issn1001-053x.2014.09.004

Ge, H. Y., Chen, C., Li, H. B., Wang, S., Zhou, J., and Jing, B. X. (2014). Experiment on the Law of Strength Increasing of Ultrafine Tailings Filling Body. Mod. Mining 7, 10-13. doi:10.3969/j.issn.1674-6082.2014. 07.004

Hong, W., Sun, G. H., and Liang, S. B. (2021). Study on Synergetic Mechanism of Ore Pillar-Filling Body System. Metal Mine 03, 40-45. doi:10.19614/j.cnki.jsks. 202103006

Li, X., Peng, K., Peng, J., and Hou, D. (2021a). Effect of thermal Damage on Mechanical Behavior of a fine-grained sandstone. Arab J. Geosci. 14, 1212. doi:10.1007/s12517-021-07607-0

Li, X., Yang, S., Wang, Y., Nie, W., and Liu, Z. (2021b). Macro-micro Response Characteristics of Surrounding Rock and Overlying Strata towards the Transition from Open-Pit to Underground Mining. Geofluids 2021, 1-18. doi:10.1155/2021/5582218

Li, X., Liu, Z., and Yang, S. (2021c). Similar Physical Modeling of Roof Stress and Subsidence in Room and Pillar Mining of a Gently Inclined MediumThick Phosphate Rock. Adv. Civil Eng. 2021, 1-17. doi:10.1155/2021/ 6686981

Lin, M., Su, C. Z., and Zhou, X. C. (2013). Stability Analysis on the Cemented Filling Body in Deep Mining Area. Morden Mining 29 (1), 42-44. doi:10.3969/j. issn.1674-6082.2013.01.012 
Liu, Z. Y., Sun, W., and Zhou, X. G. (2005). Research on Rapid Testing Method for Gas Diffusion Coefficient of concrete. Concrete 11, 3-5. doi:10.3969/j.issn.10023550.2005.11.001

Liu, W., Zhang, X., Fan, J., Zuo, J., Zhang, Z., and Chen, J. (2020a). Study on the Mechanical Properties of Man-Made Salt Rock Samples with Impurities. J. Nat. Gas Sci. Eng. 84, 103683. doi:10.1016/j.jngse.2020.103683

Liu, W., Zhang, Z., Fan, J., Jiang, D., Li, Z., and Chen, J. (2020b). Research on Gas Leakage and Collapse in the Cavern Roof of Underground Natural Gas Storage in Thinly Bedded Salt Rocks. J. Energ. Storage 31, 101669. doi:10.1016/j.est. 2020.101669

Liu JG, J. G., Li, X. W., and He, T. (2020). Application Status and prospect of Backfill Mining in Chinese Coal Mines. J. China Coal Soc. 45 (1), 141-150. doi:10.13225/j.cnki.jccs.YG19.1063

Lu, H. J., Liang, P., Gan, D. Q., and Zhang, S. L. (2017). Research on Flow Sedimentation Law of Filling Slurry and Mechanical Characteristics of Backfill Body. Rock Soil Mech. 38 (Suppl. 1), 263-270. doi:10.16285/j.rsm.2017.S1.032

Qi, C., and Fourie, A. (2019). Cemented Paste Backfill for mineral Tailings Management: Review and Future Perspectives. Minerals Eng. 144, 106025. doi:10.1016/j.mineng.2019.106025

Qi, C.-c. (2020). Big Data Management in the Mining Industry. Int. J. Miner Metall. Mater. 27, 131-139. doi:10.1007/s12613-019-1937-z

Qiu, H., Zhang, F., Liu, L., Hou, D., and Tu, B. (2020). Influencing Factors on Strength of Waste Rock Tailing Cemented Backfill. Geofluids 2020, 1-7. doi:10. 1155/2020/8847623

Qiu, H., Zhang, F., Liu, L., Huan, C., Hou, D., and Kang, W. (2022). Experimental Study on Acoustic Emission Characteristics of Cemented Rock-Tailings Backfill. Constr. Build. Mater. 315, 125278. doi:10.1016/j. conbuildmat.2021.125278

Shi, J. S., Qian, R. S., Zhang, Y. S., Chen, Y. D., Qian, J. J., and Liu, Z. Y. (2021). Advances in Gas Permeability Test Methods and its Relationships with Durability for Cementitious Materials. Mater. Rep. 35 (1), 10. doi:10.11896/cldb.20040016

Wang, W. N., and Xu, Z. H. (2018). Experimental Research on the Permeability of Cemented Backfill Body. Mining Res. Develop. 38 (07), 56-60. doi:10.13827/j. cnki.kyyk.2018.07.012

Wang, P., Chen, S. E., Chen, Z. Q., and Mao, X. B. (2009). Dynamic Response of Carbon Dioxide Diffusion and Reaction in Porous Cementitious Back-Filling Material. J. Mining Saf. Eng. 36 (02), 381-387. doi:10.13545/j.cnki.jmse.2019. 02.022

Wang, G. L., Liu, W. Q., and Tao, Y. (2010). Experimental Study of Permeability in Fractured Sandstone with Sediment Particles. Mech. Eng. 32 (5), 14-17. doi:10. 6052/1000-0992-lxysj2010-050

Wu, D., Sun, G. H., and Huang, G. (2015). Experimental and Simulation Study on Seepage Characteristics of Cemented Tailings Backfill. J. Cent. South Univ. 46 (03), 1050-1057. doi:10.11817/j.issn.1672-7207.2015.03.036

Xu, X. C., Xie, Q. Q., Chen, F., Wang, J., and Wu, W. T. (2008). Acid Mine Drainage and Heavy Metal Pollution from Solid Waste in the Tongling Mines, China. Acta Geol. Sin. 01, 150-157. doi:10.3321/j.issn:1000-9515.2008.01.015

Yang, Q. R., and Zhu, B. R. (2003). Testing Methods on the Permeability and Influence Factors of Permeability of Concrete. Low Temperature Architect. Techn. 05, 9-12. doi:10.3969/j.issn.1001-6864.2003.05.003
Yao, H. H., Cai, L. B., Liu, W., Qin, W. Q., Jiao, F., and Yang, C. R. (2021). Current Status and Development of Comprehensive Utilization of Waste Rock in Metal Mines in China. Chin. J. Nonferrous Met. 31 (06), 1649-1660. doi:10.11817/j. ysxb.1004.0609.2021-35986

Yin, S., Shao, Y., Wu, A., Wang, H., Liu, X., and Wang, Y. (2020). A Systematic Review of Paste Technology in Metal Mines for Cleaner Production in China. J. Clean. Prod. 247, 119590. doi:10.1016/j.jclepro.2019.119590

Yuan, X. L., and Xu, K. C. (2004). Advances in Solid Waste Treatment and Disposal Technology for China's Metal Mines. Metal Mine 06, 46-49+60. doi:10.3321/j. issn:1001-1250.2004.06.014

Zhang, J., Zhang, Q., Huang, Y., Liu, J., Zhou, N., and Zan, D. (2011a). Strata Movement Controlling Effect of Waste and Fly Ash Backfillings in Fully Mechanized Coal Mining with Backfilling Face. Mining Sci. Techn. (China) 21 (005), 721-726. doi:10.1016/j.mstc.2011.03.003

Zhang, J., Zhou, N., Huang, Y., and Zhang, Q. (2011b). Impact Law of the Bulk Ratio of Backfilling Body to Overlying Strata Movement in Fully Mechanized Backfilling Mining. J. Min Sci. 47 (1), 73-84. doi:10.1134/S1062739147010096

Zhang, J. X., Zhang, Q., Ju, F., Zhou, N., Li, M., and Sun, Q. (2018). Theory and Technique of Greening Mining Integrating Mining, Separating and Backfilling Indeep Coal Resources. J. China Coal Soc. 43 (2), 377-389. doi:10.13225/j.cnki. jccs.2017.4102

Zhang, P. S., Hou, J. Q., Zhao, C. Y., and Li, T. H. (2020). Experimental Study on Seepage Characteristics of Red sandstone with Different Confining Pressure and Different Damage Degree. Chin. J. Rock Mech. Eng. 39 (12), 2405-2415. doi:10.13722/j.cnki.jrme.2020.0266

Zhong, X., Chen, Z., Li, Y., Ding, K., Liu, W., Liu, Y., et al. (2020). Factors Influencing Heavy Metal Availability and Risk Assessment of Soils at Typical Metal Mines in Eastern China. J. Hazard. Mater. 400, 123289. doi:10.1016/j. jhazmat.2020.123289

Zhu, M. B., Cheng, J. Y., Cui, W. X., and Yue, H. (2019). Comprehensive Prediction of Coal Seam Thickness by Using In-Seam Seismic Surveys and Bayesian Kriging. Acta Geophys. 67 (4), 825-836. doi:10.1007/s11600-019-00298-y

Conflict of Interest: The authors declare that the research was conducted in the absence of any commercial or financial relationships that could be construed as a potential conflict of interest.

Publisher's Note: All claims expressed in this article are solely those of the authors and do not necessarily represent those of their affiliated organizations, or those of the publisher, the editors, and the reviewers. Any product that may be evaluated in this article, or claim that may be made by its manufacturer, is not guaranteed or endorsed by the publisher.

Copyright (c) 2022 Qiu, Zhang, Sun, Liu, Zhao and Huan. This is an open-access article distributed under the terms of the Creative Commons Attribution License (CC $B Y$ ). The use, distribution or reproduction in other forums is permitted, provided the original author(s) and the copyright owner(s) are credited and that the original publication in this journal is cited, in accordance with accepted academic practice. No use, distribution or reproduction is permitted which does not comply with these terms. 